\title{
Preliminary tests on a microfluidic device to study pore clogging during biocementation
}

\author{
Filipe Felício ${ }^{1}$, Vania Silverio $^{2}$, Sofia Duarte $^{3}$, Ana Galvão $^{1}$, Gabriel Monteiro ${ }^{3}$, Susana Cardoso $^{2}$, Rafaela Cardoso $^{1, *}$ \\ ${ }^{1}$ University of Lisbon, IST/CERIS, Portugal \\ ${ }^{2}$ University of Lisbon, INESC-MN, Lisbon, Portugal; IST, Portugal \\ ${ }^{3}$ University of Lisbon,iBB/IST, Portugal
}

\begin{abstract}
Soil improvement using ureolytic bacteria or other biological agents is a promising technique currently under investigation. It is based on the precipitation of calcium carbonate (biocement) due to the enzymatic hydrolysis of urea. The biocement produced clogs the soil pores, consequently bonding the soil grains and increasing overall strength and stiffness while reducing permeability. This study focused mainly on pore clogging effects. The effect of the enzyme and feeding solution concentrations was studied in small test tubes to find the maximum amount of precipitate found when changing the concentrations of both. Based on it, selected concentrations of enzyme and feeding solution were tested in a microfluidic device conceived to mimic a two-dimensional uniform porous size medium. Qualitatively, the amount of precipitate was proportional to that of the concentrations used. The location of the precipitate was clearly related with the direction of fluid flow during inoculation. These preliminary results highlight the fact that the use of alternative testing devices such as the one developed is a potential tool for the study of clogging phenomena occurring during this treatment.
\end{abstract}

\section{Introduction}

Soil improvement using ureolytic bacteria or other biological agents is a promising technique currently under investigation [1-3]. It is based on the fact that calcium carbonate (biocement) is precipitated due to the hydrolysis of urea in the presence of a calcium source (feeding solution). The biocement clogs the soil pores and consequently bonds the soil grains, increases soil overall strength and stiffness and reduces the medium permeability [4-7].

The study presented here is focused mainly on pore clogging effects, which is important because: (i) the treatment requires accessible pores; (ii) enough quantity of feeding solution (calcium source) must be provided to precipitate the intended quantity of biocement; (iii) fluid must circulate for treatment progress (add more biological agent and/or feeding solution); (iv) fluid velocity must be small enough to avoid washing away the precipitate and biological agents; (v) pore geometry depends on grading size distribution and void ratio; (vi) permeability depends on pore geometry and reduces with the progression of the treatment; and (vii) bonds geometry, and consequently the soil improvement achieved, depends on the amount of biocement and pore geometry [3].

In this study, the dosage definition of enzyme and feeding solution was done in small test tubes to find the influence of concentration on the maximum amount of precipitate. The results allowed defining the concentrations of enzyme and feeding solution to be used in the tests performed in a microfluidic device conceived to mimic a two-dimensional uniform porous size media. Using this device, it was possible to monitor the precipitation process along time, which was quantified using image processing tools. To the authors knowledge, this is the first study taking advantage of microfluidic devices to quantify the amount of precipitation during biocementation.

\section{Enzyme and feeding solution used}

The feeding solution was prepared using yeast extract $(2$ $\mathrm{g} / \mathrm{L})$, ammonium sulphate $\left(\mathrm{NH}_{4}\right) 2 \mathrm{SO}_{4}(1 \mathrm{~g} / \mathrm{L})$, urea (12.14 g/L), calcium chloride $\mathrm{CaCl}_{2}(110.8 \mathrm{~g} / \mathrm{L})$, ammonium chloride $\mathrm{NH}_{4} \mathrm{Cl} \quad(10 \mathrm{~g} / \mathrm{L})$, sodium bicarbonate $\mathrm{NaHCO}_{3}(2.12 \mathrm{~g} / \mathrm{L})$ and distilled water up to $1 \mathrm{~L}$. The feeding solution used in the tests resulted from a volume dilution of this solution in distilled water.

Concentrated samples were prepared by mixing feeding solution and urease enzyme from jack bean (Canavalia ensiformis) dissolved in PBS (phosphate buffered saline, $\mathrm{pH}$ 7), in well-established concentrations. Control samples of distilled water were also used throughout the experiments.

\footnotetext{
* Corresponding author: rafaela@,civil.ist.utl.pt
} 


\section{Preliminary tests to define dosages}

Two types of tests were conducted aiming to: (i) find the optimal concentration of urease enzyme (Test 1) and (ii) study the behavior of a constant urease solution in presence of different feeding dosages (Test 2). In both tests, the amount of enzyme and feeding solution were mixed and left to react at constant temperature of $20^{\circ} \mathrm{C}$, forming a precipitate. The dry mass was measured after a period of $24 \mathrm{~h}$. The precipitate was analysed using X-Ray diffraction to confirm the presence of calcium carbonate in the form of calcite in each precipitated mass, confirming the hydrolysis of urea [8].

The solutions were prepared in microcentrifuge tubes (eppendorf type). Each tube was filled with a $1 \mathrm{~mL}$ volume of the different solutions. After a $24 \mathrm{~h}$ reaction period. The tubes were centrifuged, and the supernatant was discarded. Then the tubes were left $24 \mathrm{~h}$ at $60^{\circ} \mathrm{C}$ to complete drying of the remaining precipitate.

The results of Test 1 are presented in Figure 1 for the case when the feeding solution was $86 \%(860 \mu \mathrm{L}$ feeding solution in $1 \mathrm{~mL}$ distilled water). The control case (1 mL distilled water) without adding feeding solution serves to quantify the amount of enzyme precipitate. From Figure 1 the conclusions are that: (i) the reaction with the feeding solution occurred and is dependent on the enzyme concentration and (ii) for urease concentrations larger than $15 \mathrm{mg} / \mathrm{mL}$ the precipitate mass does not increase significantly. The behavior of the measured dry mass is very similar to the theoretical production of calcium carbonate computed using stoichiometry, indicating that it should be the major component of the precipitates, as also revealed by the control sample results. This was the amount of enzyme used in Test 2.

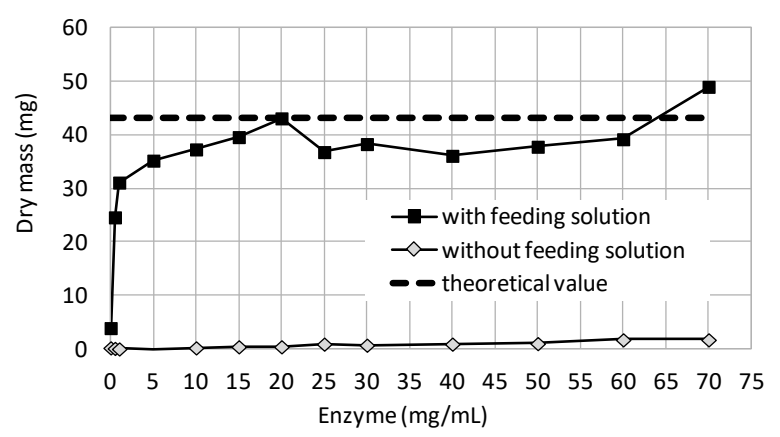

Fig. 1. Urease concentration analysis fixing the amount of feeding solution to $86 \%$.

In Test 2 the formation of precipitate was investigated considering also the case where only the feeding solution (absence of enzyme) was used, to discard the formation of other precipitates in the solution (Figure 2). The results confirm that the amount of precipitate formed is directly proportional to the quantity of feeding solution available. These results also show sample concentrations of $15 \mathrm{mg} / \mathrm{mL}$ follow the theoretical production of calcium carbonate for feeding solution volumes up to around $800 \mu \mathrm{L}$. This may indicate an inhibition mechanism of urease enzyme.
The amount of feeding solution is in accordance with Test 1 results presented in Figure 1 and allows fixing the volume of feeding solution to be used to the value where the experimental results were closer to the theoretical values, as is when maximum precipitate can be produced when urease concentration is $15 \mathrm{mg} / \mathrm{mL}$.

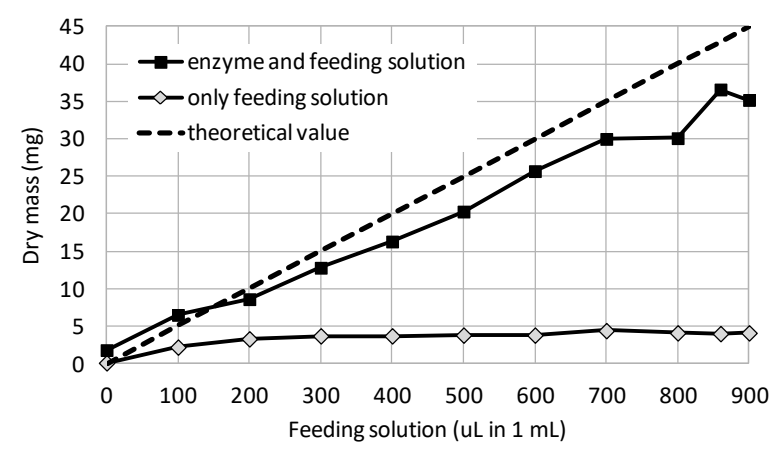

Fig. 2. Analysis of feeding solution dosage (urease concentration is $15 \mathrm{mg} / \mathrm{mL}$ in all experiments).

\section{Microfluidic device}

\subsection{Description of the microfluidic device}

The microfluidic device is composed by a $2 \mathrm{~mm}$-thick top acrylic plate and a $3 \mathrm{~mm}$-thick bottom acrylic plate. Figure 3 presents the two plates and their respective elements and dimensions. In the bottom plate, a channel with $1 \mathrm{~mm}$ height (where the flow occurs) and several obstacles in form of columns with $1 \mathrm{~mm}$ diameter were milled using micromilling techniques [9](fig. 4).
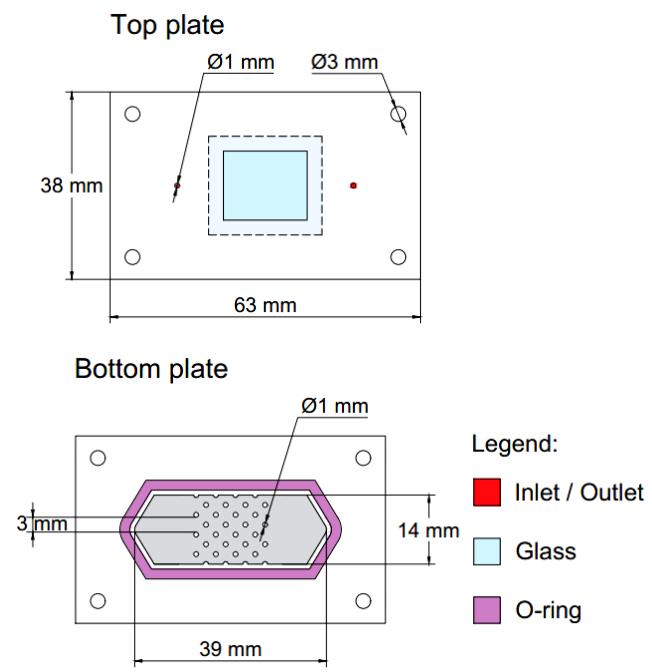

Fig. 3. Top view 2D schematics of the microfluidic device.

In the top plate, two inlets/outlets with $1 \mathrm{~mm}$ diameter were drilled. The cover plate is a square borosilicate glass, inserted for improved visualization of the flow below. Both plates were joined using four M3 screws and a uniform layer of silicone. The device is totally symmetrical, enabling flow direction to occur both ways. A picture of the final device is presented in 
Figure $4 \mathrm{c}$ ). The total volume of solution completely filling the device is inferior to $0.5 \mathrm{~mL}$.

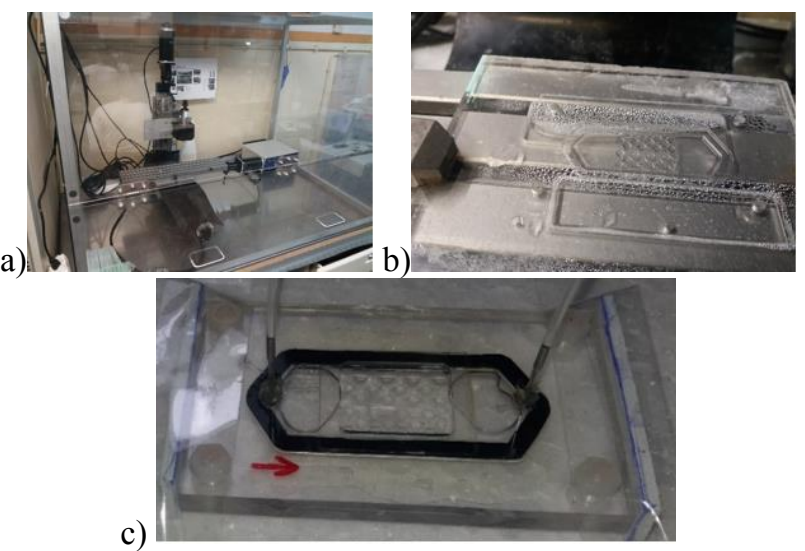

Fig. 4. a) CNC milling machine (INESC-MN); b) microfluidic device under construction; c) finished microfluidic device.

\subsection{Experiments on the microfluidic device}

The purpose of these tests was to reproduce the behavior of laboratorial results of Test 2 previously presented. Therefore, five solutions were injected on the device, with composition listed in Table 1. Solutions without enzyme ( $0 \%$ urease concentration) and without feeding solution $(0 \%$ in volume) were included as control tests. The other cases correspond to increasing percentages in volume of the feeding solution including the value where larger dry mass of precipitate for fixed $15 \mathrm{mg} / \mathrm{mL}$ of enzyme was found.

Table 1. Solutions injected in the microfluidic device.

\begin{tabular}{|c|c|}
\hline $\begin{array}{c}\text { Urease concentration } \\
(\mathbf{m g} / \mathbf{m} \mathbf{L})\end{array}$ & $\begin{array}{c}\text { \% (in volume) of } \\
\text { feeding solution }\end{array}$ \\
\hline 15 & 0 \\
\hline 15 & 10 \\
\hline 15 & 50 \\
\hline 15 & 86 \\
\hline 15 & 100 \\
\hline
\end{tabular}

A special equipment, which photograph isshown in fFigure 5, was used to fix both the device and a digital camera, creating a stationary in position. Backlight illumination was produced by a LED plate in the bottom allowingto provide the contrast between the white precipitate and the transparent fluidic flow obstacles.

The injection of the different solutions in the microfluidic device was done with a $5 \mathrm{~mL}$ syringe. A reaction period of $24 \mathrm{~h}$ followed. Photographs were taken periodically during the process and analysed using digital tools.

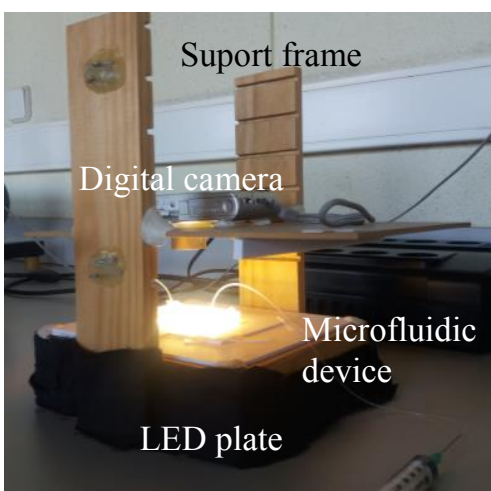

Fig. 5. Experimental setup for monitoring the reactions occurring in the microfluidic device during an experiment.

\subsection{Data analysis}

The digital images taken of the different experiments, such as those shown in Figure 6, were analyzed with the MATLAB image processing toolbox. A script was written to evaluate RGB values on the images, ranging from 0 to 255 (Table 2). Blue was identified as having higher intensity variation in the images, and was used for image analysis.

Table 2. Blue intensity range obtained for different test samples

\begin{tabular}{|c|c|}
\hline Experiment & Blue intensity range \\
\hline $15 \mathrm{mg} / \mathrm{ml}$ urease & $0-125$ \\
\hline $15 \mathrm{mg} / \mathrm{ml}$ urease + & $100-135$ \\
$10 \%$ feeding & \\
\hline $15 \mathrm{mg} / \mathrm{ml}$ urease + & $0-130$ \\
$50 \%$ feeding & \\
\hline $15 \mathrm{mg} / \mathrm{ml}$ urease + & $0-130$ \\
$86 \%$ feeding & \\
\hline $100 \%$ feeding & $0-115$ \\
\hline
\end{tabular}

a)

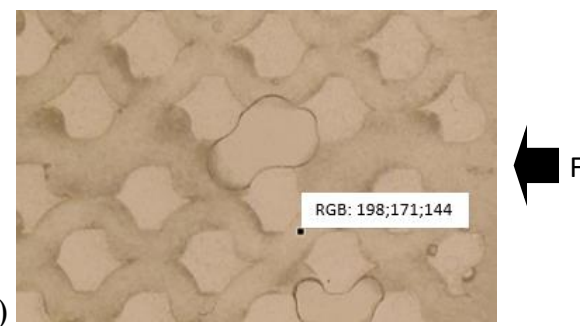

Fluid flow

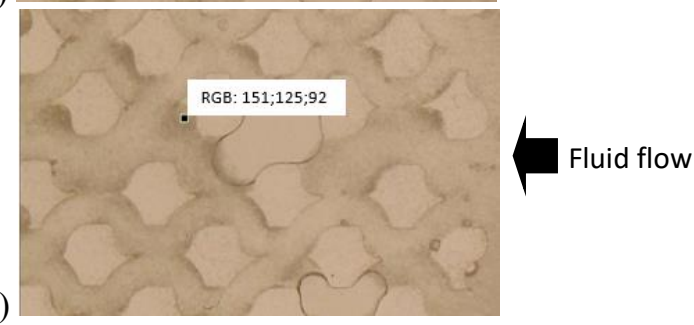

Fig. 6. Choice of the color interval having as reference areas: a) without precipitate; b) with precipitate.

Considering data from Table 2 , it is worth to note that, for the percentage of feeding solution of $10 \%$, the intensity information was influenced by the presence of gas bubbles dispersed in the system, and for this reason an additional intensity correction had to be done. 
Figure 7 presents the pixels count resulting from the different experiments. In the presence of enzyme, the amount of precipitate was proportional to that of the concentrations used, considering the increasing percentages of volume of feeding solution (except 10\%). The curves found for $10 \%$ and $100 \%$ of feeding solution (no enzyme used) are out of the alignment, the first case due to the interference of air bubbles, leading to different calibration constants, and the second case probably due to the different nature of the precipitate, as also shown in Figure 2.

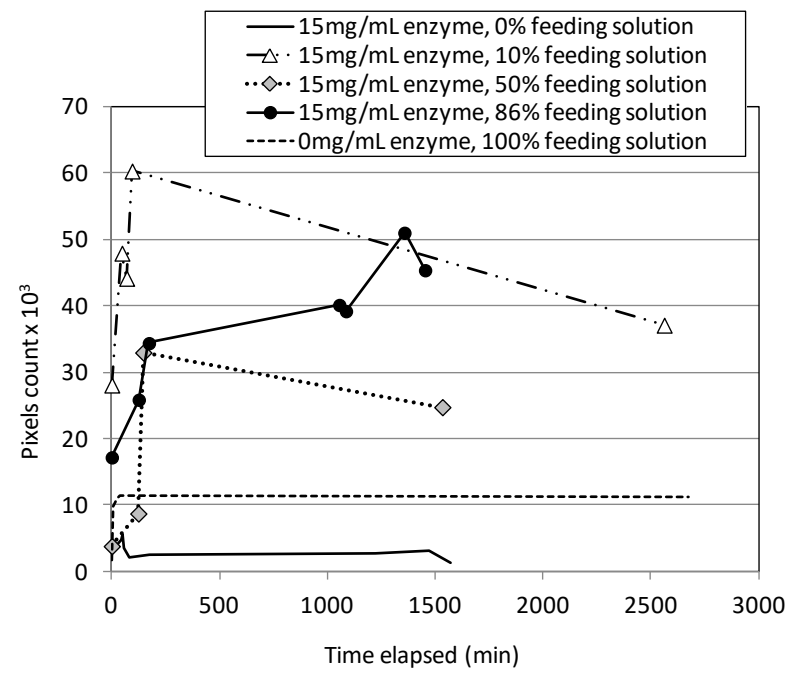

Fig. 7. Experimental results.

Finally, the original images of the $15 \mathrm{mg} / \mathrm{mL}+86 \%$ feeding solution test and the respective processed images are sequentially presented in Figure 8 . The location of the precipitate is seen to be related with the direction of fluid flow during inoculation, as the precipitate tends to accumulate behind the vertical obstacles. This is also visible in Figure 6.

\section{Conclusions}

These preliminary results highlight the fact that the use of alternative testing devices such as the one developed is a useful tool for studying clogging phenomena occurring during biocementation.
This work was partially funded by CERIS, project BIOCLOG and FCT project PTDC/ECI-EGC/32590/2017.

\section{References}

1. Ivanov, V., and Chu, J. (2008). Reviews in Environmental Science and Biotechnology, 7(2), 139-153 (2008)

2. Mitchell, J. K., and Santamarina, J. C.. Journal of Geotechnical and Geoenvironmental Engineering, 131(10), 1222-1233 (2005)

3. Whiffin, V. S. Microbial CaCO3 Precipitation for the Production of Biocement. Phd Thesis, Murdoch University, Perth, Australia (2004)

4. Gomez, M. G., Martinez, B. C., DeJong, J. T., Hunt, C. E., deVlaming, L. A., Major, D. W., and Dworatzek, S. M. Proceedings of the Institution of Civil Engineers - Ground Improvement, 168(3), 206-216 (2015)

5. Ng, W., Lee, M., and Hii, S. World Academy of Science, Engineering and Technology, 62(2), 723729 (2012)

6. Van Paassen, L. A., Ghose, R., van der Linden, T. J. M., van der Star, W. R. L., and van Loosdrecht, M. C. M. J. Geotechnical and Geoenvironmental Engineering, 136(12), 1721-1728 (2010)

7. Van Paassen, L. A., Harkes, M. P., Van Zwieten, G. A., Van Der Zon, W. H., Van Der Star, W. R. L., and Van Loosdrecht, M. C. M.. Scale up of BioGrout: A biological ground reinforcement method. (Proc. 17th Int. Conf. Soil Mechanics and Geotechnical Engineering), 2328-2333 (2009)

8. Felício, F. Development of methodologies to visualize pore clogging phenomena, MSc thesis, Instituto Superior Técnico, Universidade de Lisboa, Portugal (in Portuguese) (2018)

9. Silvério, V. and Cardoso,S. Microfabrication Techniques for Microfluidic Devices in book: Complex Fluid-Flows in Microfluidics, Ed. Galindo-Rosales ISBN 978-3-319-59592-4 (2017)

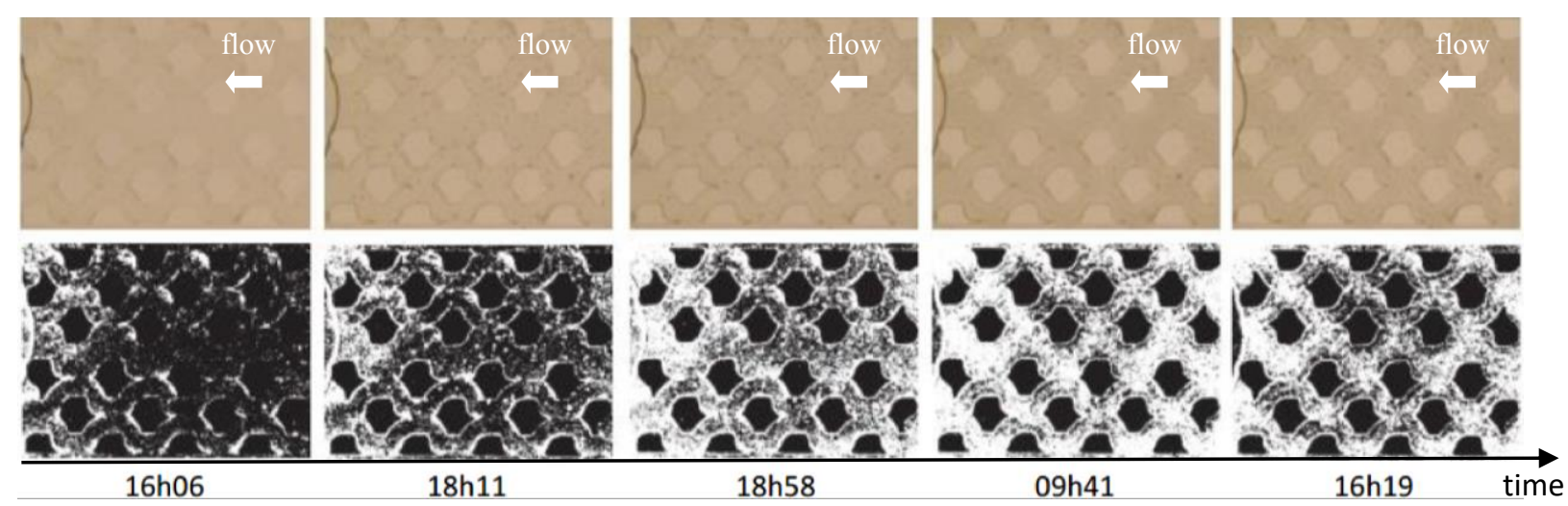

Fig. 8. Time lapse of unprocessed (top) and processed images (bottom) for $15 \mathrm{mg} / \mathrm{ml}$ urease $+86 \%$ feeding solution experiment. 